\title{
Influência da Disponibilidade de Alimentos de Origem Antrópica sobre o Comportamento Natural de Nasua nasua (Linnaeus, 1766) no Parque Nacional da Serra dos Órgãos, Teresópolis, Rio de Janeiro
}

\author{
Ana Elisa de Faria Bacellar1, Cecília Cronemberger², Lorena de Souza Soares², David de Sousa Stein², \\ Hayssa Alves de Oliveira Dumard Siqueira², Isabela Deiss de Farias² \& Úlyma Ramos Hentz Pinto 2
}

Recebido em 27/11/2020 - Aceito em 10/08/2021

\footnotetext{
${ }^{1}$ Centro Nacional de Avaliação da Biodiversidade e de Pesquisa e Conservação do Cerrado/CBC/ICMBio, Brasil. <ana.bacellar@icmbio.gov.br,

${ }^{2}$ Parque Nacional da Serra dos Órgãos/ICMBio, Brasil. <cecilia.faria@icmbio.gov.br, loresouzabiologia@gmail.com, davidsteinbiofilm@gmail.com, haysiqueirabio@gmail.com, isabela.farias@icmbio.gov.br, ulymaramoshp@gmail.com>
}

RESUMO - A sustentabilidade da atividade turística em unidades de conservação (UCs) depende de uma gestão que busque um balanço positivo entre os impactos negativos e a proteção da biodiversidade. A aproximação de visitantes a animais silvestres e oferta de alimentos é um dos impactos potenciais da visitação pública em UCs a ser monitorado e minimizado. Nesse contexto, o objetivo do trabalho foi quantificar a frequência relativa em que quatis (Nasua nasua) acessam lixeiras no Parque Nacional da Serra dos Órgãos e testar a eficiência de dois modelos de trava para dificultar esse acesso. Para descrever o comportamento dos quatis, foram realizadas 358 horas de observação, em 2013 e 2017/2018, usando o método de "amostragem de todas as ocorrências". Para testar a eficiência das travas, foram monitoradas por armadilha fotográfica três lixeiras iscadas: uma com trava, modelo "iguaçu", outra com modelo "tijuca" e uma lixeira controle, sem trava. Os comportamentos mais frequentes foram forrageamento natural $(31 \%)$, deslocamento $(14 \%)$, vocalização $(10 \%)$ e alimentar-se de lixo (10\%), sugerindo que os quatis mantêm seu comportamento natural, consumindo alimentos de origem antrópica de forma complementar. Ambas as travas foram eficientes, mas houve maior insistência dos quatis na lixeira "iguaçu", possivelmente devido à atratividade do odor como consequência da vedação imperfeita. Em um cenário de visitação crescente, recomenda-se instalar a trava "tijuca" nas lixeiras do parque, assim como placas, orientando visitantes a não alimentarem e manterem distância segura dos quatis. Espera-se assim, evitar acidentes e enfraquecer o hábito oportunista dos quatis, diminuindo a interferência da presença humana em seu comportamento.

Palavras-chave: Quatis, ecologia comportamental; uso público; impactos da visitação; pesquisa aplicada à gestão de unidades de conservação; travas de segurança.

\section{Anthropogenic Food Availability Influence on the Natural Behavior of Nasua nasua (Linnaeus, 1766) in the Serra dos Órgãos National Park, Teresópolis, Rio de Janeiro}

\begin{abstract}
The sustainability of tourism activity in protected areas (PAs) depends on management that seeks a positive balance between negative impacts and the protection of biodiversity. The approach of visitors to wild animals and food supply is one of the potential impacts of public visitation in APs to be monitored and minimized. In this context, the objective of this study was to quantify the relative frequency at which coatis (Nasua nasua) access dumps in the Serra dos Órgãos National Park and to test the efficiency of two lock models to prevent these accesses. To describe the behavior of the coatis, 358 hours of observation were carried out in 2013 and 2017/2018, using the "sampling of all occurrences" method. To test the efficiency of the locks, three baited dumps were monitored by camera trap, in filming mode, one with an "iguaçu" model lock, another with a "tijuca" model and a control without a lock. The most frequent behaviors were natural foraging (31\%), displacement (14\%), vocalization (10\%) and eating garbage (10\%), suggesting that coatis maintain their natural behavior, using foods of anthropic origin complementarily. Both locks were efficient, but there was a greater insistence of coatis in the "iguaçu" bins, possibly due to the attractiveness of the odor as a consequence of the imperfect seal. In a scenario of increasing visitation, it is recommended to install the "tijuca" lock in the park's bins, and signs advising visitors not to feed and keep a safe distance from coatis.
\end{abstract}


Thus, it is hoped to avoid accidents and weaken the opportunistic habit of coatis, reducing the interference of human presence in their behavior.

Keywords: Coatis; behavioral ecology; public use; visitation impacts; research applied to protected area management; security locks.

\title{
Influencia de la Disponibilidad de Alimentos Antropogénicos en el Comportamiento Natural de Nasua nasua (Linnaeus, 1766) en el Parque Nacional Serra dos Órgãos, Teresópolis, Rio de Janeiro
}

\begin{abstract}
RESUMEN - La sostenibilidad de la actividad turística en Áreas Protegidas (AP) depende de una gestión que busque un equilibrio positivo entre los impactos negativos y la protección de la biodiversidad. Acercar a los visitantes a los animales silvestres y la oferta de alimentos es uno de los impactos potenciales de las visitas públicas en las AP que deben ser monitoreadas y minimizadas. En este contexto, el objetivo del trabajo fue cuantificar la frecuencia relativa en la que los coatíes (Nasua nasua) acceden a los vertederos en el Parque Nacional Serra dos Órgãos y probar la eficiencia de dos modelos de esclusas para dificultar este acceso. Para describir el comportamiento de los coatíes, se realizaron 358 horas de observación en 2013 y 2017/2018, utilizando el método de "muestreo de todas las ocurrencias". Para probar la eficiencia de las cerraduras, se monitorearon por cámara tres papeleras cebadas: una con modelo "iguaçu", otra con modelo "tijuca" y un control de basura sin cerradura. Los comportamientos más frecuentes fueron la búsqueda de alimento natural (31\%), el desplazamiento (14\%), la vocalización (10\%) y el comer basura (10\%), sugiriendo que los coatíes mantienen su comportamiento natural, consumiendo alimentos de origen antrópico de forma normal. complementario. Ambas cerraduras resultaron eficientes, pero hubo mayor insistencia de los coatíes en el vertedero "iguaçu", posiblemente por el atractivo del olor como consecuencia del imperfecto sellado. En un escenario de creciente visitación, se recomienda instalar la esclusa de "tijuca" en los botaderos del parque, así como letreros que indiquen a los visitantes no alimentarse y mantenerse a una distancia segura de los coatíes. Se espera que, para evitar accidentes y debilitar el hábito oportunista de los coatíes, se reduzca la interferencia de la presencia humana en su comportamiento.
\end{abstract}

Palabras-clave: Coatíes; ecología del comportamiento; uso público, impactos de la visitación; investigación aplicada al manejo de áreas protegidas; cerraduras de seguridade.

\section{Introdução}

O turismo em áreas protegidas de países em desenvolvimento, em especial em zonas tropicais, vinha crescendo anualmente (ICMBio, 2020), antes de deflagrado o surto da COVID-19, caracterizada como pandemia pela Organização Mundial da Saúde em 11 de março de 2020. No Brasil, a visitação pública em unidades de conservação (UCs) federais cresceu cerca de $270 \%$ nos últimos 10 anos, e 24\% só de 2018 para 2019 (ICMBio, 2020). Estudos evidenciam que a visitação traz benefícios econômicos e sociais relevantes para o entorno das UCs (Souza et al., 2017; Leung et al., 2019). Para cada $R \$ 1,00$ investido no sistema brasileiro de UCs, são produzidos $\mathrm{R} \$ 7,00 \mathrm{em}$ benefícios econômicos, além de outros benefícios indiretos para diferentes tipos de negócios e para as comunidades locais, gerando emprego, renda e valor agregado (Souza et al., 2017).
O Instituto Chico Mendes de Conservação da Biodiversidade (ICMBio) considera a visitação em UCs uma estratégia de sensibilização da sociedade para a importância da conservação da natureza e tem investido fortemente no modelo de concessão de serviços de visitação para a iniciativa privada, como já acontece há muitos anos nos Parques Nacionais (PARNAs) da Tijuca e da Serra dos Órgãos (RJ), do Iguaçu (PR) e de Fernando de Noronha (PE) e, mais recentemente, nos PARNAs da Chapada dos Veadeiros (GO), Itatiaia (RJ) e Pau Brasil (BA). Esse investimento traz perspectivas de aumento no número de visitantes nas UCs administradas pelo ICMBio, passadas as restrições impostas pela crise sanitária provocada pela pandemia de COVID-19.

Apesar dos impactos positivos, a presença de visitantes pode causar impactos negativos que venham a comprometer (i) a manutenção da diversidade biológica e dos recursos genéticos, (ii) 
a proteção das espécies ameaçadas de extinção $e$ (iii) a preservação e a restauração da diversidade de ecossistemas naturais, aspectos elencados como os três primeiros objetivos do Sistema Nacional de Unidades de Conservação (SNUC) (Brasil, 2000). A visitação desordenada pode causar a introdução de espécies exóticas invasoras, a compactação e erosão do solo, mudanças na estrutura e composição da vegetação e poluição (Turton \& Stork, 2008; Ballantyne \& Pickering, 2015; Pickering \& Norman, 2017; Wraith \& Pickering, 2017).

Possíveis impactos sobre a fauna incluem a disseminação de doenças parasitárias de animais domésticos para animais silvestres (Moraes et al., 2019), o aumento do estresse fisiológico para algumas espécies (Arlettaz et al., 2015; Senigaglia et al., 2016), diminuição do sucesso reprodutivo (Müllner et al., 2004) e diferentes distúrbios de comportamento, como diminuição de interações sociais e aumento do tempo em habitat de baixa qualidade (Aguilar-Melo et al., 2013), interrupção de atividades e alteração em comportamentos de vigilância, forrageamento e reprodução (Burger \& Gochfeld, 1998; Brown et al., 2012; Geffroy et al., 2015; Fortin et al., 2016; Goldenberg et al., 2017) e alteração na frequência de emissões vocais (Stein, 2015). Mais recentemente, as incertezas em relação à transmissão da COVID-19 entre humanos $e$ animais silvestres causam preocupações que se somam aos demais impactos potenciais da atividade de visitação em áreas protegidas (Mostafavi et al., 2021).

A perspectiva de crescimento da visitação pública em PARNAs brasileiros requer cuidado e responsabilidade para uma gestão da visitação voltada não apenas ao aumento do número de visitantes $e$ ao consequente lucro das empresas concessionárias, mas à qualidade dos serviços prestados, à qualidade da experiência do visitante $e$ à sua segurança, além de buscar minimizar os impactos negativos gerados pela atividade.

Para garantir a sustentabilidade do turismo e gestão de áreas protegidas, isto é, considerando seus impactos econômicos, sociais e ambientais atuais e futuros, atendendo às necessidades dos visitantes, indústria, meio ambiente $e$ comunidades locais (UNWTO e UNEP, 2005), a International Union for Conservation of Nature (IUCN) recomenda que este seja apropriado, bem administrado e apoie os objetivos de conservação, a partir de um conjunto de diretrizes que são referência em nível mundial para gestores de áreas protegidas (Leung et al., 2019). A manutenção da sustentabilidade da atividade turística depende fortemente da sua gestão para garantir um balanço positivo entre os impactos negativos e a proteção da biodiversidade (Buckley et al., 2016; Mossaz et al., 2015).

A aproximação entre visitantes $e$ animais silvestres e a oferta de alimentação aos animais são alguns dos impactos indesejáveis a serem monitorados e evitados, tanto devido à possibilidade de ocorrência de acidentes, quanto ao risco de transmissão de doenças e de mudanças no comportamento desses animais (Roe et al., 1997; Orams, 2002; Barcelos, 2018). A oferta de alimento pode alterar atividades naturais, uma vez que os itens alimentares oferecidos pelos humanos, normalmente com alto teor calórico, podem reduzir o tempo relativo de forrageamento e caça bem como aumentar o tempo de descanso e socialização (Saj et al., 1999), além da possibilidade de tornar os animais agressivos para obter a qualquer custo o alimento habitualmente consumido (Orams, 2002).

Os quatis (Nasua nasua, Linnaeus, 1766), possuem hábito oportunista e são facilmente avistados por visitantes em UCs, estando sujeitos à interação com humanos. A espécie é comum na América do Sul, ocupando habitat arborizados, incluindo florestas decíduas e perenes (Redford \& Stearman, 1993). Pertence à Ordem Carnivora e alimenta-se primordialmente de invertebrados, pequenos vertebrados, folhas e frutos, o que caracteriza a espécie como onívora (Emmons \& Feer, 1997; Beisegel et al., 2001; AlvesCosta et al., 2004).

Na sede Teresópolis do Parque Nacional da Serra dos Órgãos (PARNASO), estado do Rio de Janeiro, os quatis frequentemente interagem com visitantes (Fig. 1) e procuram alimento nas lixeiras (observação pessoal, Fig. 2). Em resposta a esse estímulo, os animais podem sofrer alterações comportamentais, que podem ser caracterizadas como uma domesticação indireta, ou tornarem-se agressivos, aumentando o risco de acidentes com visitantes (Osram, 2002).

No Parque Nacional do Iguaçu, os frequentes acidentes com visitantes levaram a unidade de conservação a adotar uma medida emergencial de manejo, translocando alguns indivíduos de quati, considerados extremamente 
agressivos, de forma a removê-los dos grupos que faziam parte. De 2013 a 2019, a unidade registrou uma média de 298 acidentes anuais envolvendo quatis e visitantes. Só em 2018 , foram registrados 526 acidentes. O maior número mensal de registros $(\mathrm{n}=92)$ foi observado em fevereiro de 2019 (relatórios de gestão do PARNA do Iguaçu, dados não publicados). São números que servem de alerta para outras UCs com ocorrência da espécie e que investem no aumento do número de visitantes. O PARNA do Iguaçu, que recebe, em média, mais de um milhão e meio de visitantes por ano, ultrapassou a marca de dois milhões de visitantes em 2019, sendo a segunda unidade de conservação mais visitada do Brasil, perdendo apenas para o PARNA da Tijuca (ICMBio, 2020). Além de ter uma visitação expressiva, o PARNA do Iguaçu possui a experiência mais antiga entre as UCs federais com concessão de serviços de apoio à visitação.

Além dos efeitos negativos da visitação pública no comportamento dos quatis, a oferta de alimentos estranhos à sua dieta natural $e$ a ingestão eventual de restos de plástico, papel, isopor e outros tipos de resíduos sólidos podem acarretar engasgos, problemas digestivos ou outros problemas para a saúde do animal, como demonstrado para outras espécies da fauna (Guebert, 2008; Riekehr Júnior et al., 2017).

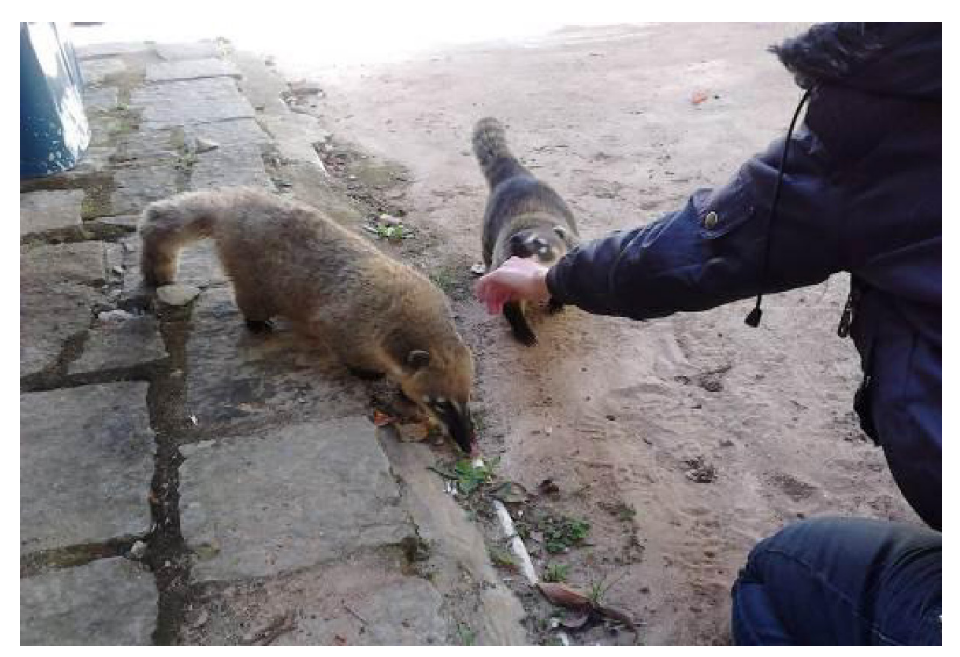

Figura 1 - Interação entre quatis e visitante do Parque Nacional da Serra dos Órgãos, Teresópolis, RJ.

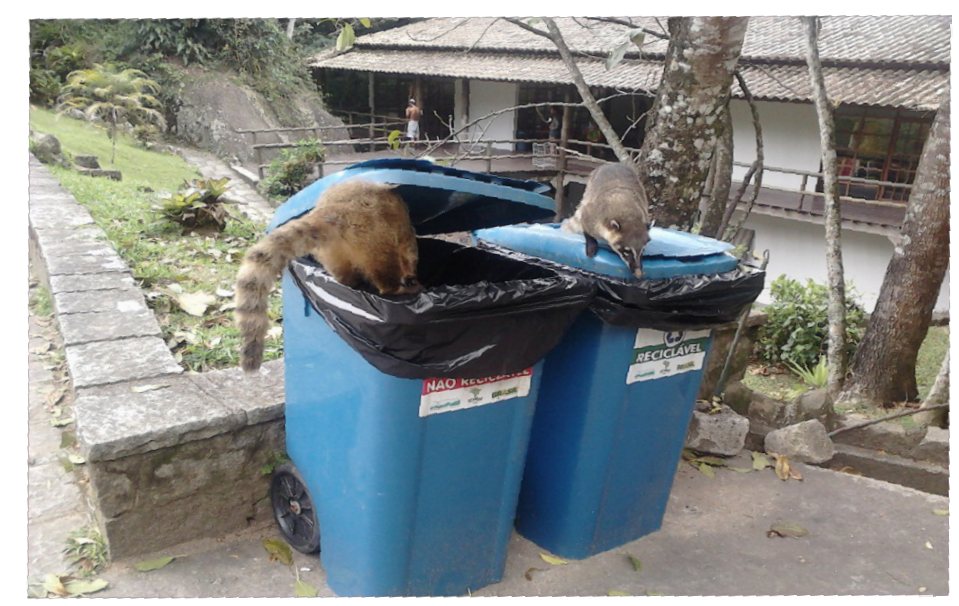

Figura 2 - Quatis acessando o conteúdo de lixeiras próximas à piscina natural na sede Teresópolis do Parque Nacional da Serra dos Órgãos, Rio de Janeiro. 
Diante da tendência de aumento da visitação pública no PARNASO (tendência que pode ser observada no painel dinâmico de informações de gestão do ICMBio (ICMBio, 2020), associado à preocupação com a saúde das populações de quatis que ocupam as áreas mais visitadas da unidade de conservação $e$ com a segurança dos visitantes, este estudo teve como objetivo quantificar a frequência em que os grupos de Nasua nasua acessam as lixeiras distribuídas ao longo da área de uso intensivo do PARNASO, comparada às demais categorias de comportamento observadas, e testar a eficiência de dois diferentes modelos de trava para os latões de lixo dispostos na sede Teresópolis, a fim de evitar que os animais acessem o conteúdo dos latões.

\section{Material e Métodos}

\section{Área de estudo}

O Parque Nacional da Serra dos Órgãos (PARNASO) está localizado no estado do Rio de Janeiro, a aproximadamente $16 \mathrm{~km}$ ao norte da Baía de Guanabara, abrangendo cerca de 20.000ha nos municípios de Petrópolis, Teresópolis, Magé e Guapimirim. O clima é caracterizado como mesotérmico brando superúmido, com temperatura média variando entre $13^{\circ}$ e $23^{\circ} \mathrm{C}$ e índice pluviométrico médio anual entre $2.300 \mathrm{~mm}$ e $3.000 \mathrm{~mm}$, com verões brandos, sem estação seca e com abundância das precipitações nos meses de verão (Cronemberger e Viveiros de Castro, 2007). Nessa região são classificadas quatro fitofisionomias de Mata Atlântica: Floresta Pluvial Baixo Montana, Floresta Pluvial Montana, Floresta Pluvial Alto Montana e Campos de Altitude (Rizzini, 1979).

Essa unidade de conservação tem importante representatividade na Mata Atlântica, por ser um fragmento de floresta com um gradiente altitudinal intenso, chegando a atingir $2.263 \mathrm{~m}$ (Silva, 2003). A sede principal da unidade está localizada no município de Teresópolis, nas coordenadas geográficas de 22²6'55.7' S e 4259'08.6”' W. O projeto foi desenvolvido na Zona de Uso Intensivo da sede Teresópolis do PARNASO (Fig. 3), onde está situada a administração central e a maior quantidade de infraestrutura predial e de visitação da UC (centro de visitantes, piscina natural, lanchonete, alojamentos, residências funcionais $e$ outras edificações). Além da sede Teresópolis, o PARNASO conta com uma sede em Guapimirim e outra em Petrópolis. Toda a UC recebe entre 150 e 200 mil visitantes por ano, sendo a maior parte registrada em Teresópolis, sede que chega a receber até 2.500 visitantes em um só dia na alta temporada, entre dezembro e março (ICMBio, 2020).

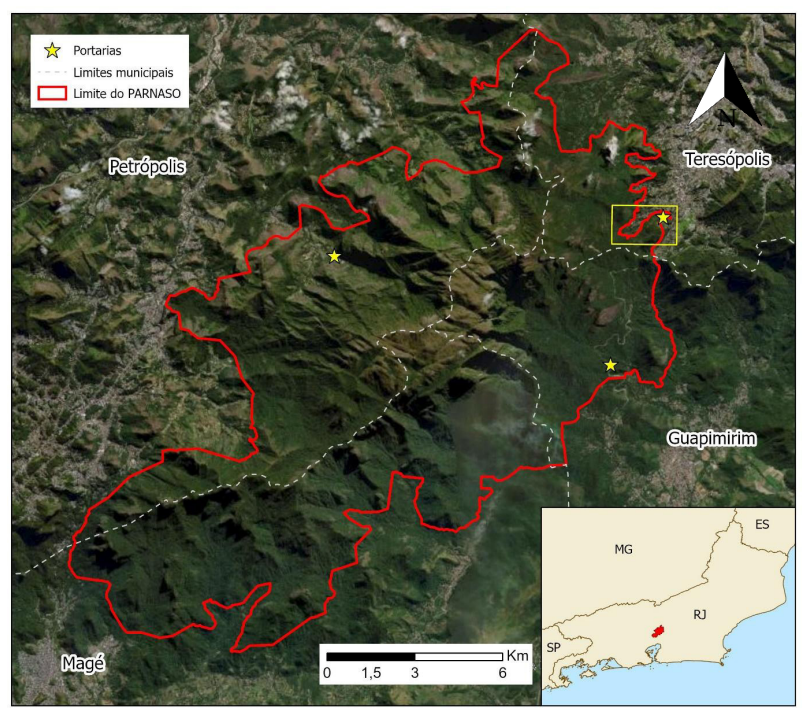

Figura 3 - Localização geográfica do Parque Nacional da Serra dos Órgãos, Rio de Janeiro, Brasil. As sedes administrativas estão representadas pelas estrelas amarelas nos municípios de Petrópolis, Teresópolis e Guapimirim. 
A Zona de Uso Intensivo da Sede Teresópolis abrange uma piscina de água natural, com entorno jardinado, áreas de piquenique, poços, uma estrada interna (Estrada da Barragem) e acessos a diversas trilhas que se iniciam nessa estrada. A área de estudo foi escolhida por ser a região do PARNASO onde há maior produção de resíduos sólidos e a maior interação entre quatis e seres humanos. Entre 2010 e 2021, a UC manteve um contrato de concessão para a operação de serviços de apoio à visitação, como sistema de cobrança e controle de ingressos, operação de campings e abrigos de montanha. O contrato incluía a adoção de programa de recolhimento de lixo em áreas naturais e a separação de lixo reciclável (disponível em: https://www.icmbio.gov.br/portal/concessaode-servicos), estando de acordo com as diretrizes da IUCN para a sustentabilidade e gestão dos resíduos sólidos. No entanto, na prática, a gestão de resíduos permanecia como obrigação única do
ICMBio. A partir de agosto de 2021, com o fim do contrato, toda a gestão da visitação voltou a ser executada diretamente pelo ICMBio.

\section{Amostragem}

Para descrever o comportamento dos quatis, foram realizadas observações em dois períodos distintos: de janeiro a julho de 2013 e de julho de 2017 a março de 2018. As observações foram realizadas na área de uso intensivo da Sede Teresópolis, onde circulam visitantes $e$ funcionários e onde ficam distribuídos latões de lixo, sempre em pares, sendo um destinado ao lixo orgânico e outro ao lixo reciclável. Os pontos mais próximos às lixeiras foram escolhidos para observar o comportamento dos quatis nas eventuais interações com humanos $e$ acesso às lixeiras (Fig. 4).

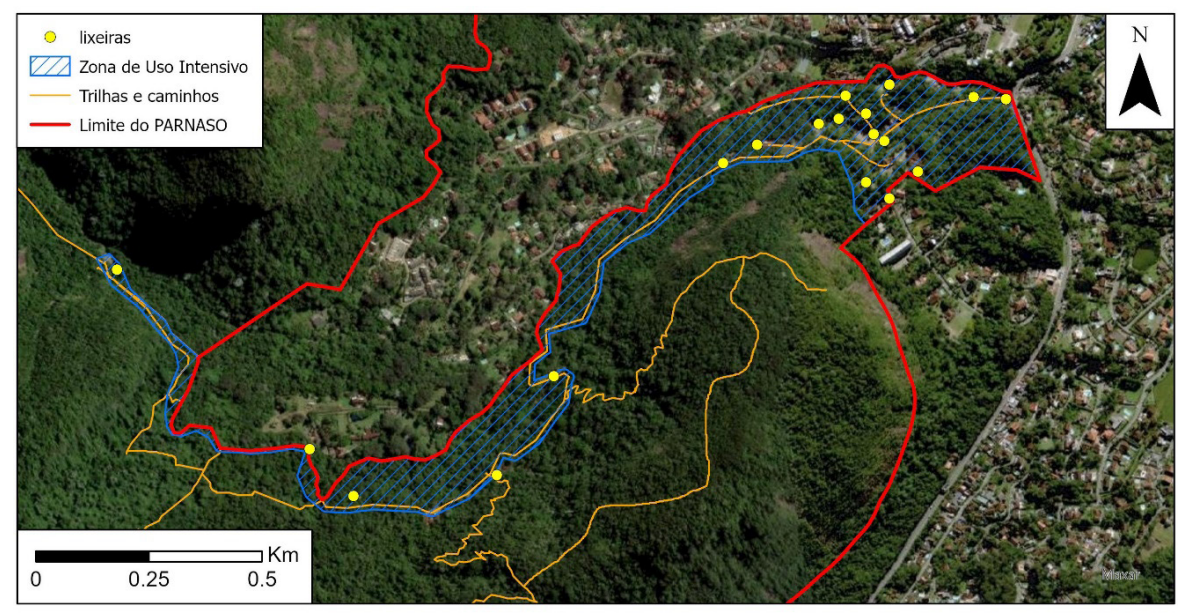

Figura 4 - Localização dos latões de lixo ao longo da Zona de Uso Intensivo na sede Teresópolis do Parque Nacional da Serra dos Órgãos, Rio de Janeiro, Brasil.

Para registro do comportamento, foi usado o método de "amostragem de todas as ocorrências", no qual se registra tudo que é observado, ou seja, tudo o que o animal faz. Esse método é utilizado na fase de familiarização com o objeto de estudo e na padronização da metodologia através da qualificação dos comportamentos e elaboração de um repertório comportamental, também sendo recomendado para o registro de comportamentos fortuitos, raros ou inesperados (Del-Claro, 2004).
Adicionalmente, foram realizados registros por meio de imagens (foto e vídeo), para auxiliar na comprovação do que foi observado, permitindo a realização de descrições minuciosas de situações, interações, comportamentos, lugares e informações necessárias à compreensão do objeto do estudo. O registro de imagens auxilia na interpretação dos ambientes e dos diferentes fatos observados, uma vez que a captação de dados por imagens torna o estudo ainda mais dinâmico (Del-Claro, 2004; Ipiranga, 2016). 
Em ambos os períodos de observação, foi utilizado o mesmo repertório de 11 categorias de comportamento, listadas na Tabela 1. As observações foram feitas de duas a quatro vezes por semana, em ambos os períodos, totalizando um esforço amostral de 358 horas de observação, sendo 150 no primeiro período de amostragem e 108 no segundo período.

Tabela 1 - Descrição do repertório de categorias de comportamento de Nasua nasua observadas em ambos os períodos de amostragem (janeiro a julho de 2013 e julho de 2017 a março de 2018) no Parque Nacional da Serra dos Órgãos, Teresópolis, RJ.

\begin{tabular}{|c|c|}
\hline $\begin{array}{l}\text { Categoria de } \\
\text { comportamento }\end{array}$ & Descrição \\
\hline Acasalar & $\begin{array}{l}\text { Reunir macho e fêmea para } \\
\text { procriação }\end{array}$ \\
\hline Alimentar-se de lixo & $\begin{array}{l}\text { Revirar lixo ou alimenta-se } \\
\text { de lixo }\end{array}$ \\
\hline Alimentar-se naturalmente & $\begin{array}{l}\text { Comer frutos, sementes e/ou } \\
\text { pequenos animais }\end{array}$ \\
\hline Ameaçar/entrar em conflito & $\begin{array}{l}\text { Ameaçar, ser ameaçado ou } \\
\text { disputar/lutar com outro } \\
\text { quati }\end{array}$ \\
\hline Beber água & $\begin{array}{l}\text { Tomar água de bromélias, } \\
\text { poças etc. }\end{array}$ \\
\hline $\begin{array}{l}\text { Afagar/brincar/realizar } \\
\text { limpeza social }\end{array}$ & $\begin{array}{l}\text { Interação entre quatis para } \\
\text { troca de afagos, higienização } \\
\text { de outro quati ou brinca- } \\
\text { deira }\end{array}$ \\
\hline $\begin{array}{l}\text { Coçar-se ou fazer autolim- } \\
\text { peza }\end{array}$ & $\begin{array}{l}\text { Higienizar-se, lamber-se, } \\
\text { coçar-se, catar-se ou sacudir- } \\
\text {-se }\end{array}$ \\
\hline Descansar & $\begin{array}{l}\text { Descansar sobre troncos e/ } \\
\text { ou galhos das árvores ou } \\
\text { ficar parado }\end{array}$ \\
\hline Deslocar-se & $\begin{array}{l}\text { Andar e/ou correr sobre o } \\
\text { solo ou utilizar árvores e } \\
\text { galhos para se locomover }\end{array}$ \\
\hline Forragear & $\begin{array}{l}\text { Revirar folhas e/ou terra } \\
\text { a procura de alimento, } \\
\text { locomover-se farejando ou } \\
\text { farejar parado }\end{array}$ \\
\hline Vocalizar & Emitir sons vocais \\
\hline
\end{tabular}

\section{Experimento com diferentes sistemas de travas para os latões de lixo do PARNASO}

Para testar e comparar a eficiência de dois diferentes modelos de trava para os latões de lixo, ambas com o objetivo de dificultar ou impedir o acesso dos quatis ao interior das lixeiras, foi realizado um experimento entre março e julho de 2013. O experimento foi conduzido nos fundos do prédio de administração do PARNASO, onde circulam apenas funcionários autorizados, que foram informados sobre a importância de não interferirem no experimento.

Foram utilizados três latões de lixo idênticos em tamanho e forma. Em um dos latões foi instalada uma trava do modelo denominado "iguaçu", adaptado do Parque Nacional del Iguazu, na Argentina, usando um mecanismo semelhante, mas com outro tipo de material, composta por duas peças de alumínio com uma dobradiça, facilmente encontradas em lojas ferragens, como "porta-cadeado" (Fig. 5A e 5B). No segundo latão, foi instalada uma trava do modelo denominado "tijuca", desenvolvida pelo funcionário Lucio Meirelles Palma para ser usada no Parque Nacional da Tijuca (Fig. 5C e 5D). O terceiro latão foi usado como controle, sem trava alguma. Nos três recipientes, foram inseridas iscas idênticas em conteúdo e quantidade, contendo banana e sardinha (Fig. 6). O conteúdo era substituído a cada dois dias para manter o odor atrativo. Para filmar e comparar o comportamento dos quatis acessando cada uma das três lixeiras, foi instalada uma armadilha fotográfica da marca Bushnell $₫$, posicionada à frente dos latões (Fig. $5 \mathrm{E}$ ), ligada permanentemente em modo filmagem.

\section{Análise de dados}

Os indivíduos de N. Nasua não foram distinguidos entre si por marcações individuais, de forma que nossas amostras, tanto para a frequência de comportamentos, como para testar os diferentes modelos de travas em lixeiras, são dependentes. As frequências relativas de cada categoria de comportamento foram obtidas a partir da soma do número de registros em cada uma das 11 categorias de comportamento divididas pelo total de registros, multiplicado por 100 . 
Para inferir se houve preferência dos quatis em relação a algum tipo de lixeira, foi realizado um teste $\mathrm{Q}$ de Cochran, usando o software RStudio, versão 1.3.1093. No teste foram comparadas as proporções de vídeos em que pelo menos um quati tentava acessar cada uma das lixeiras (lixeira controle: lixeira "Tijuca" e lixeira "Iguaçu"). Cada vídeo foi considerado uma ocasião, onde era registrada a presença ou ausência de quatis em cada um dos três tratamentos.
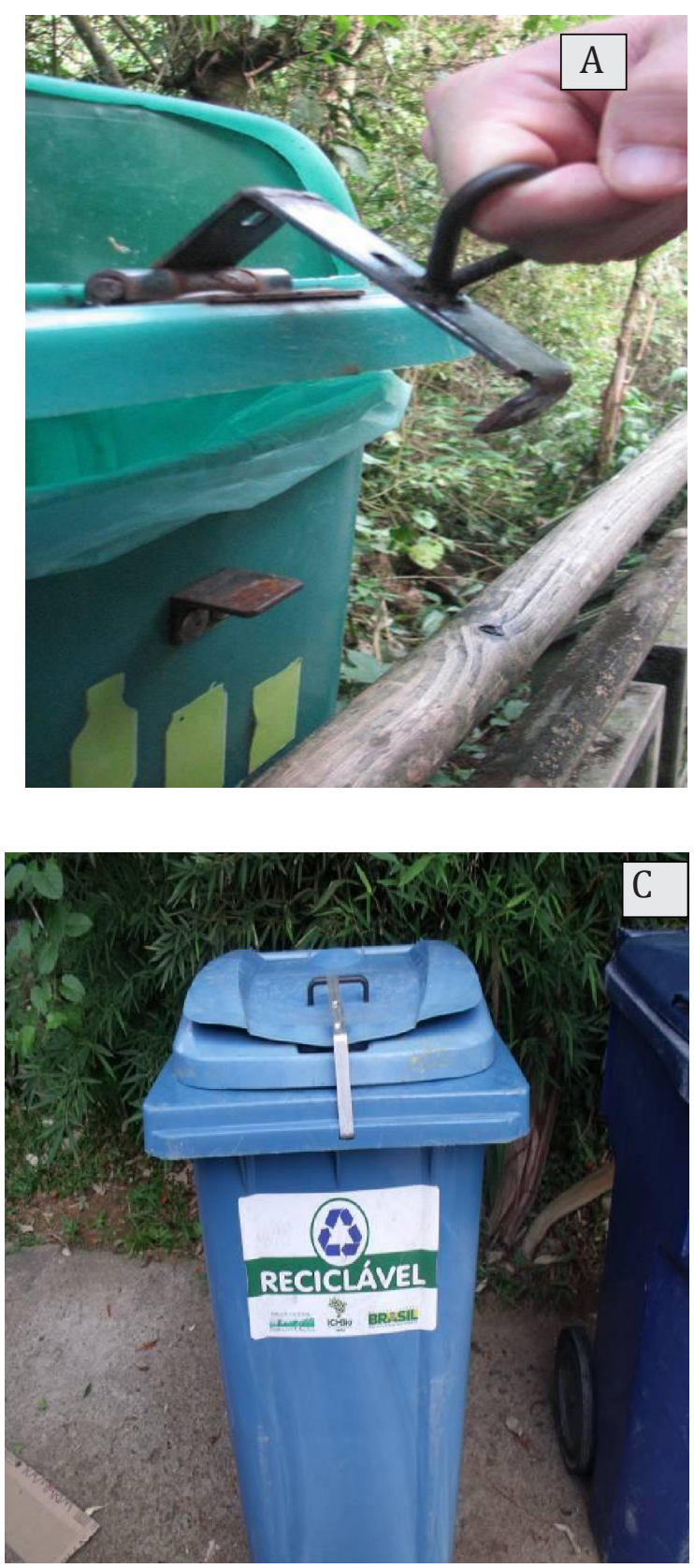

Foi registrado ainda o tempo total de permanência de quatis sobre cada lixeira (em segundos). Outros fatores como estratégias de espaçamento social e geometria de grupo que, sabidamente, influenciam nas táticas de forrageamento de quatis e nas taxas individuais de ingestão alimentar (Hirsch et al., 2019) não foram considerados neste estudo.
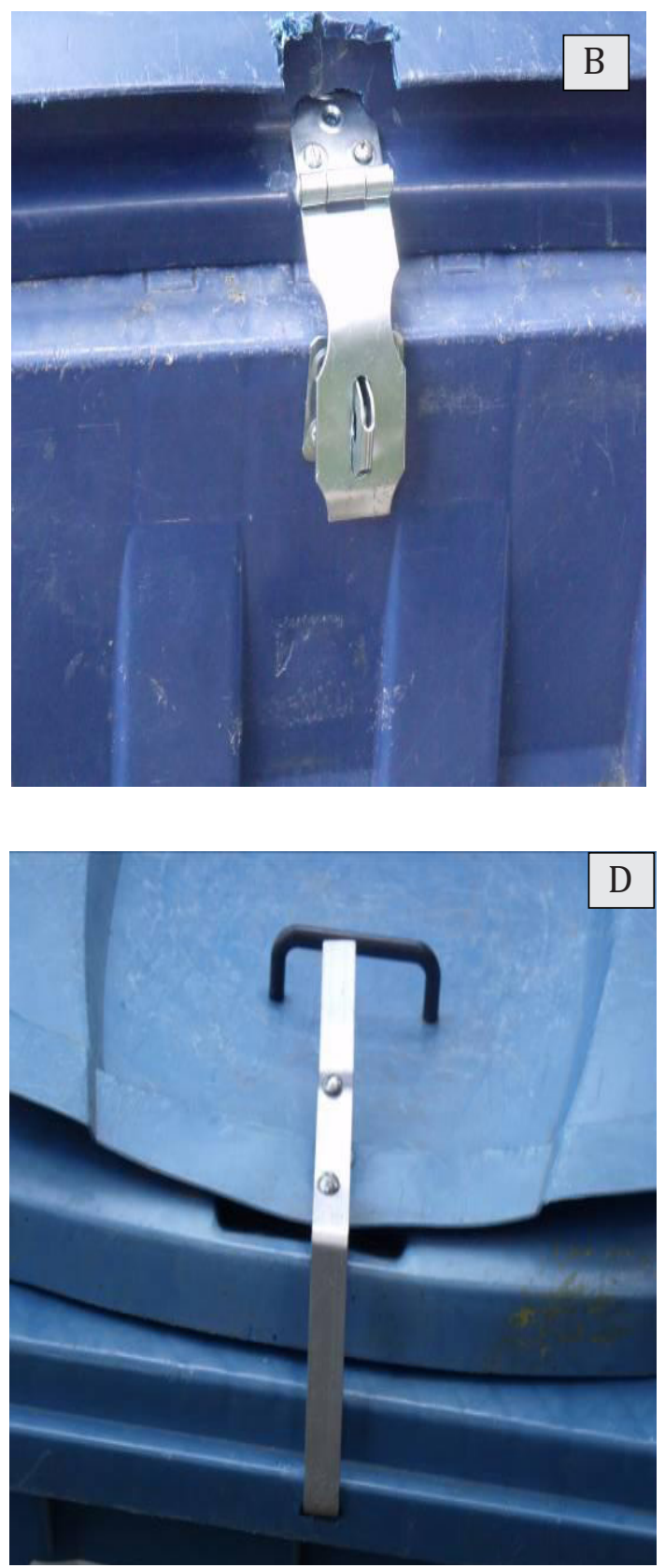


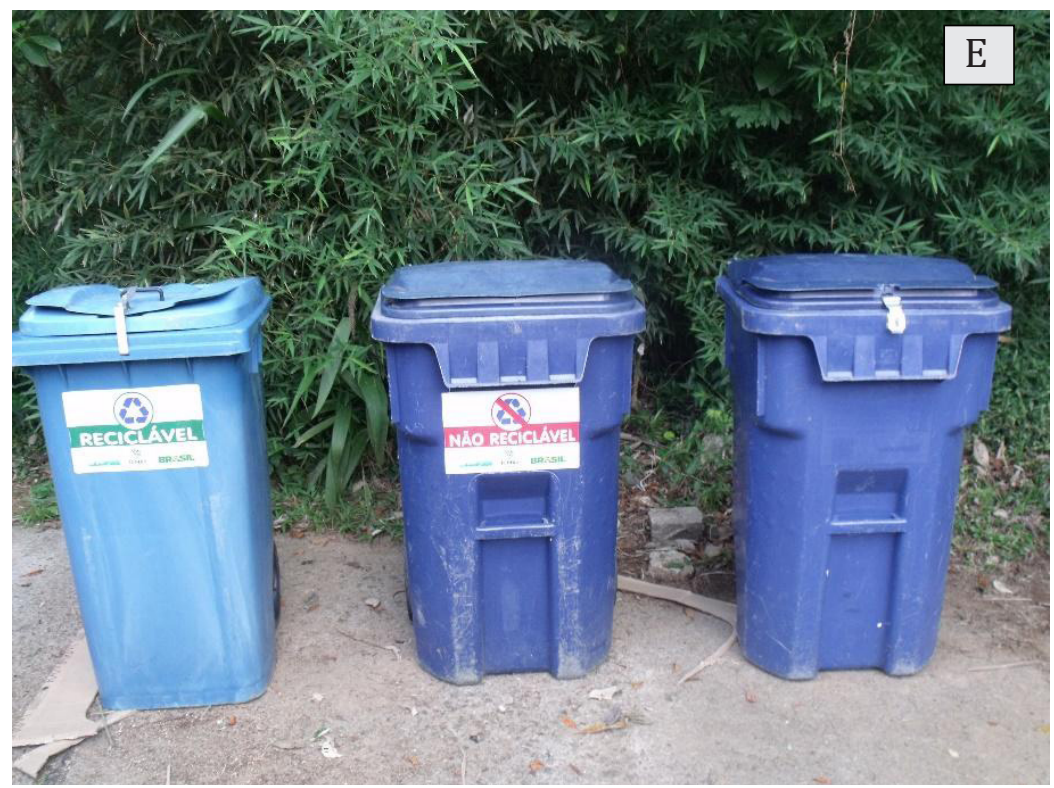

Figura 5 - Travas usadas no experimento com quatis (Nasua nasua), de março a julho de 2013, para testar a eficiência de dois diferentes modelos de trava para latões de lixo no Parque Nacional da Serra dos Órgãos, Teresópolis, RJ. (A) Trava usada em lixeiras no Parque Nacional del Iguazu, Argentina; (B) trava do modelo "Iguaçu", adaptada do modelo usado no parque argentino; (C) visão geral da trava modelo "Tijuca"; (D) detalhe da trava modelo "Tijuca"; (E) disposição dos três latões do experimento (da esquerda para a direita: trava "Tijuca", controle e trava "Iguaçu").

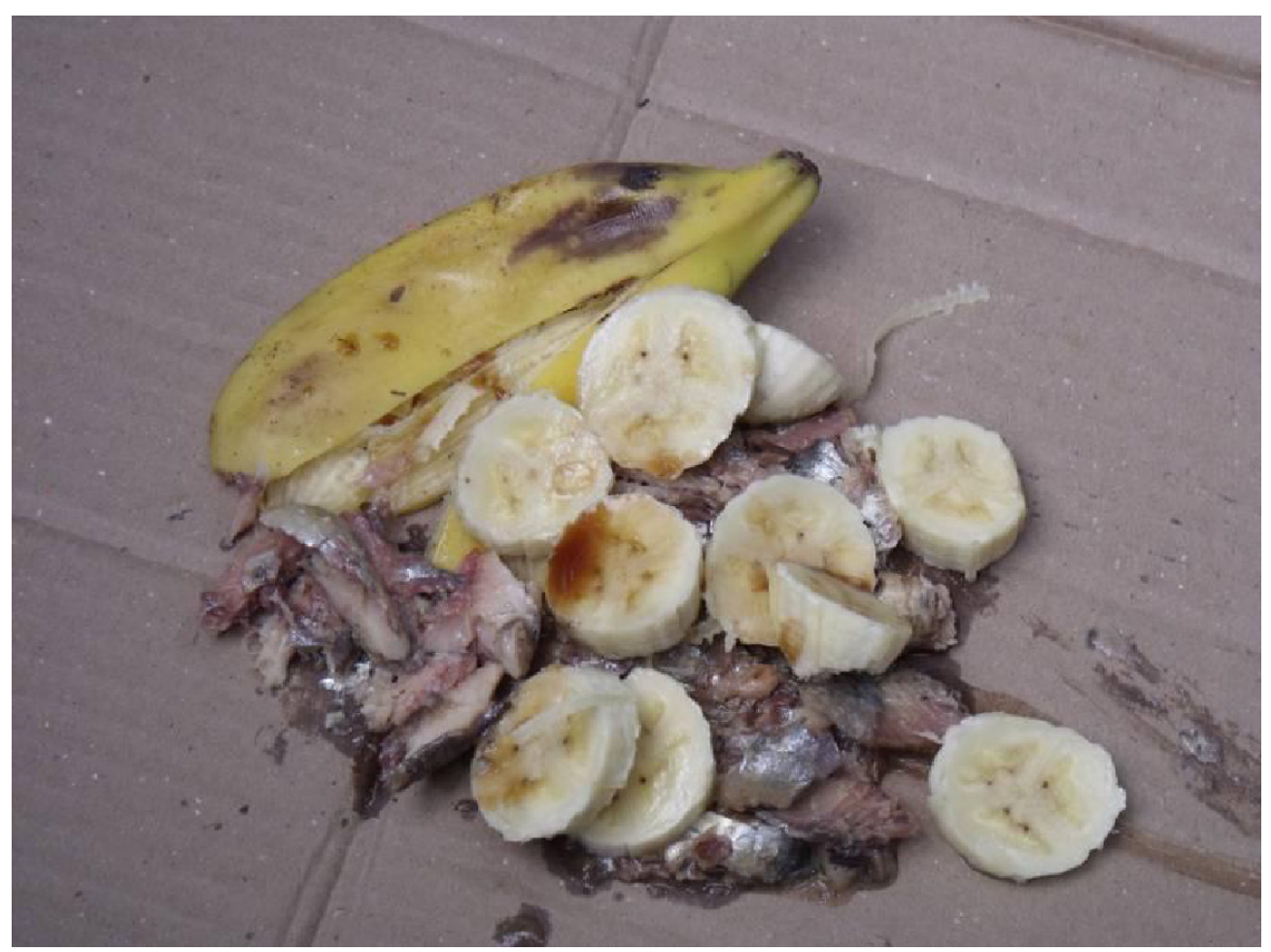

Figura 6 - Isca, composta de banana e sardinha, usada no interior de três latões de lixo do experimento com quatis (Nasua nasua), de março a julho de 2013, no Parque Nacional da Serra dos Órgãos, Teresópolis, RJ. 


\section{Resultados}

O comportamento mais frequentemente observado foi o forrageamento natural (31\%), seguido de deslocamento (14\%), vocalização (10\%) e alimentar-se de lixo (10\%). A Figura 7 mostra as frequências das 11 categorias de comportamento, das quais apenas "acasalar" não teve nenhum registro de observação. As categorias menos frequentes foram beber água (1\%), afagar/brincar/ realizar limpeza social (6\%) e ameaçar/entrar em conflito (4\%).

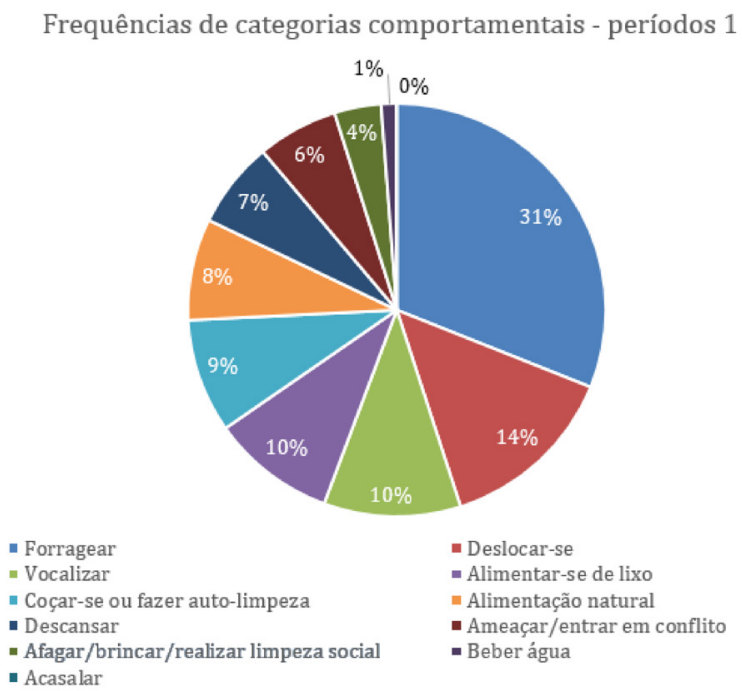

Figura 7 - Frequências relativas de categorias de comportamento de quatis (Nasua nasua), observadas de janeiro a julho de 2013 (período 1) e julho de 2017 a março de 2018 (período 2), em experimento no Parque Nacional da Serra dos Órgãos, Teresópolis, RJ.

Registros fotográficos de alguns comportamentos observados podem ser encontrados em material suplementar.

Nos quatro meses de experimento, foram obtidos 703 vídeos de 20 segundos cada, dos quais 87 apresentaram registros de 110 ocorrências de $N$. nasua. Ao todo foram acumulados 29 minutos de filmagem com a presença de pelo menos um indivíduo de quati. Em 13\% dos vídeos ( $\mathrm{n}=$ 12), os animais foram registrados, porém, não acessaram nenhuma das três lixeiras. Portanto, para as análises de comparação da eficiência das travas e preferência dos quatis, foram usados 75 vídeos.
A Tabela 2 mostra o número de vídeos nos quais houve o registro de pelo menos um indivíduo de quati visitando cada uma das três lixeiras e o tempo total que os animais permaneceram sobre ou dentro de cada uma delas.

Tabela 2 - Resultados do experimento, realizado de março a julho de 2013, para comparação entre a eficiência de dois diferentes mecanismos (trava modelo "Tijuca" e trava modelo "Iguaçu") para impedir o acesso de quatis (Nasua nasua) ao conteúdo de latões de lixo na sede Teresópolis do Parque Nacional da Serra dos Órgãos, Rio de Janeiro, Brasil.

\begin{tabular}{|c|c|c|c|c|}
\hline & $\begin{array}{l}\text { Lixeira } \\
\text { "Tijuca" }\end{array}$ & $\begin{array}{l}\text { Lixeira } \\
\text { "Iguaçu" }\end{array}$ & $\begin{array}{l}\text { Lixeira } \\
\text { sem trava } \\
\text { (controle) }\end{array}$ & Total \\
\hline $\begin{array}{l}\text { Número de } \\
\text { vídeos onde } \\
\text { aparece pelo } \\
\text { menos um quati } \\
\text { tentando aces- } \\
\text { sar as lixeiras. }\end{array}$ & $\begin{array}{c}29 \\
(39 \%)\end{array}$ & $\begin{array}{c}49 \\
(65 \%)\end{array}$ & $\begin{array}{c}37 \\
(49 \%)\end{array}$ & 75 \\
\hline $\begin{array}{c}\text { Tempo de } \\
\text { permanência de } \\
\text { quatis sobre ou } \\
\text { dentro de cada } \\
\text { lixeira (segun- } \\
\text { dos) }\end{array}$ & $\begin{array}{c}321 \\
(24 \%)\end{array}$ & $\begin{array}{c}660 \\
(50 \%)\end{array}$ & $\begin{array}{c}342 \\
(26 \%)\end{array}$ & 1.323 \\
\hline
\end{tabular}

O Teste Q de Cochran evidenciou que houve diferença entre os três tratamentos (lixeira controle, lixeira "Tijuca" e lixeira "Iguaçu"), quando comparados os vídeos com presença ou ausência de quatis em cada lixeira $(Q=8.68571428571429 ; p$ $=0.0129993341396782 ;$ graus de liberdade $=2$; nível de significância $=0,05$ ).

Considerando-se o tempo total de investimento no acesso à isca, ou seja, o tempo em que pelo menos um quati permaneceu sobre ou dentro de cada lixeira (1.323 segundos), foi observado que, em metade do tempo total investido, havia quatis tentando acessar o conteúdo da lixeira com a trava "Iguaçu" (660 segundos). Os tempos em que os animais acessaram a lixeira usada como controle ou a lixeira com a trava "Tijuca" foram muito semelhantes (342 e 321, respectivamente). Em nenhum dos registros houve sucesso no acesso ao conteúdo das lixeiras com as travas Iguaçu ou Tijuca. O acesso facilitado à lixeira controle (sem trava) fez com que a isca presente nessa lixeira fosse consumida com relativa rapidez, sempre que recolocada. 


\section{Discussão}

Nossos resultados sugerem dois pontos principais: (i) apesar de os quatis acessarem as lixeiras em busca de alimentos, o forrageamento natural foi a categoria comportamental mais registrada, com uma frequência três vezes maior comparada à "alimentação de lixo", o que pode indicar que os quatis mantêm seu comportamento natural, usando os alimentos de origem antrópica de forma complementar; (ii) utilizar um sistema de travas em lixeiras dificulta o acesso dos quatis aos resíduos descartados pelos visitantes.

Ambos os sistemas de trava "Iguaçu" ou "Tijuca" foram eficazes, pois não houve nenhum acesso ao conteúdo das lixeiras. O maior número de vídeos em que apareceram quatis sobre a lixeira com trava "Iguaçu" pode ser explicado por uma diferença na capacidade de vedação de cada tipo de trava testada, isto é, a trava Iguaçu possivelmente permitia um maior escape do odor da isca durante as tentativas de acesso dos quatis, o que aumentou a insistência em acessar o interior do latão. Na lixeira sem trava, devido à facilidade de acesso, a isca era consumida rapidamente.

A manutenção de resquícios da isca, assim como sua reposição, e a facilidade de acesso ao interior dessa lixeira, pode ter influenciado na continuidade de visitas de quatis a essa lixeira.

Mesmo em ambientes antropizados, onde há grande disponibilidade de alimento de origem humana, a dieta dos quatis ainda é predominantemente composta de itens alimentares como pequenos vertebrados, invertebrados $e$ frutos (Alves-Costa et al., 2004; Ferreira et al., 2013). Ainda assim, em quantidades pequenas, os itens alimentares de origem humana podem causar riscos à saúde dos quatis, tanto pela possibilidade de engasgo e contaminação pela ingestão de resíduos sólidos não orgânicos quanto pela ingestão de alimentos processados, industrializados de baixo valor nutricional e altas concentrações de gordura, sal e carboidratos (Riekehr Júnior et al., 2017). Alterações significativas nos níveis de glicose $e$ proteínas totais e alterações no nível plasmático de triglicerídeos já foram encontrados em quatis de uma população com contato direto com seres humanos (Riekehr Júnior et al., 2017).

Outra preocupação para a gestão da UC é que o comportamento de acesso às lixeiras provoca maior aproximação entre quatis $e$ pessoas, além de estimular a oferta de alimento por parte do visitante, representando um potencial risco de acidentes. Desde 2006, ano em que as ocorrências de acidentes com visitantes no PARNASO começaram a ser sistematizadas em meio digital, ocorreu apenas um acidente, em dezembro de 2019, envolvendo um quati e uma visitante (Leonardo Gomes, comunicação pessoal). Uma adolescente, ao se aproximar de um quati e tentar acariciá-lo, foi mordida pelo animal. Aaproximaçãodevisitantese quatis, principalmente para oferecer comida, pode acostumar os animais a este tipo de recurso, tornando-os agressivos a fim de obter maior quantidade de alimento por meio de "roubo". Esse tipo de comportamento é observado em primatas, cangurus, guaxinins e ursos em diversos locais do planeta (Orams, 2002) e, também, é observado no Parque Nacional do Iguaçu, com os próprios quatis (Ivan Carlos Baptiston e Cintia Mazon Parola, comunicação pessoal).

\section{Conclusão}

Considerando-se que o número de visitantes no PARNASO dobrou, comparando-se os períodos de 2000 a 2009 e 2010 a 2019 (ICMBio, 2020), cabe à gestão da UC atuar preventivamente, adotando medidas que visem à manutenção do comportamento natural dos quatis e à saúde das populações da espécie que habitam a UC. Com isso, recomenda-se evitar o aumento de interações indesejáveis entre quatis e seres humanos, como alimentação direta ou aproximação extrema, para que não sejam necessárias intervenções futuras mais contundentes, como o manejo de indivíduos adotado no Parque Nacional do Iguaçu.

Como uma das ações preventivas, recomenda-se a instalação da trava do modelo "Tijuca" em todos os latões de lixo distribuídos ao longo da área de visitação e administração do parque. Ao custo unitário aproximado de $R \$ 12,00$, a instalação em 19 pares de lixeira custaria à administração do PARNASO cerca de $\mathrm{R} \$ 456,00$. Como medida adicional, sugere-se a manutenção das placas informativas já existentes, que orientam os visitantes a manterem uma distância segura dos quatis e não os alimentarem, além da avaliação da necessidade de instalação de placas em outros locais, com grande circulação de visitantes. 
O monitoramento da eficiência da trava, do comportamento dos quatis e do comportamento dos visitantes são fundamentais para avaliar o sucesso da medida implantada e a adoção de eventuais ajustes para atingir os objetivos originalmente propostos. É preciso, por exemplo, avaliar a durabilidade das travas e o sucesso de uso pelos visitantes. Espera-se que, mantendo lixeiras com travas eficientes e sinalização adequada seja possível reduzir o acesso dos quatis a alimentos e restos de origem antrópica $e$ evitar acidentes envolvendo quatis e visitantes, diminuindo a interferência da presença humana no comportamento dos animais e fortalecendo a sua relação com o ambiente natural.

Recentemente o contrato de concessão de serviços de apoio à visitação da unidade foi encerrado e uma nova licitação está sendo planejada. Trata-se, portanto, de um momento oportuno para elaborar novas cláusulas contratuais visando a um balanço positivo entre os impactos da visitação na UC. Sugere-se assim que todas as medidas propostas no presente estudo sejam incluídas como medidas de mitigação de responsabilidade da concessionária, tendo em vista a corresponsabilidade da empresa pelos eventuais danos causados pela atividade de visitação à biodiversidade da UC.

As medidas propostas vão ao encontro de um dos princípios do turismo sustentável: o de aproveitar ao máximo os recursos ambientais que constituem um elemento fundamental no desenvolvimento turístico, mantendo os processos ecológicos essenciais e ajudando a conservar o patrimônio natural e a biodiversidade (Spenceley et al., 2019). As medidas também estão perfeitamente alinhadas aos objetivos institucionais do ICMBio de promover uma gestão da atividade de visitação nas UCs de forma a atenuar impactos negativos e potencializar os benefícios da atividade.

\section{Agradecimentos}

Agradecemos ao Programa PIBIC/ICMBio pela oportunidade de realização da pesquisa e ao Conselho Nacional de Desenvolvimento Científico e Tecnológico (CNPq) e Centro de Integração Empresa Escola (CIEE) pela concessão das bolsas de iniciação científica.

\section{Referências}

Aguilar-Melo, AR. et al. Behavioral and physiological responses to subgroup size and number of people in howler monkeys inhabiting a forest fragment used for nature-based tourism. Am. J. Primatol. 75, 1108-1116, 2013.

Alves-Costa CP., Fonseca GAB, Christófaro, C. Variation in the Diet of the Brown-nosed coati (Nasua nasua) In Southeastern Brazil. Journal of Mammalogy, 85(3):478-482, 2004.

Arlettaz $\mathrm{R}$ et al. Disturbance of wildlife by outdoor winter recreation: Allostatic stress response and altered activity-energy budgets. Ecol. Appl. 25, 1197-1212, 2015.

Ballantyne $\mathrm{M}$, Pickering $\mathrm{CM}$. The impacts of trail infrastructure on vegetation and soils: Current literature and future directions. J. Environ. Manage. 164, 53-64, 2015.

Barcelos DC., 2018. Efeitos da atividade turística sobre a fauna de mamíferos terrestres em um Parque Nacional brasileiro. Dissertação (Mestrado em Ecologia) Universidade de Brasília. 88p.

Beisegel BM. Notes on the coati, Nasua nasua (Carnívora: Procyonidae) in an Atlantic Forest area. Brazilian Journal of Biology,Vol 6 (4): p 689-692, 2001.

Brasil. 2000. SNUC - Sistema Nacional de Unidades de Conservação da Natureza: Lei no 9.985, de 18 de julho de 2000. Ministério do Meio Ambiente. http:// www.planalto.gov.br/ccivil_03/leis/19985.htmacessado, Acesso em 13/08/2020.

Brown CL, Hardy AR, Barber JR, Fristrup KM, Crooks $\mathrm{KR}$, Angeloni LM, The effect of human activities and their associated noise on ungulate behavior. PLoS One 7, 38-40, 2012.

Buckley RC, Morrison C, Castley JG. Net effects of ecotourism on threatened species survival. PLoS One 11, 23-25, 2016.

Burger J, Gochfeld M. Effects of ecotourists on bird behaviour at Loxahatchee National Wildlife Refuge. Environmental Conservation, p.13-21. Florida, 1998.

Cronemberger C, Viveiros de Castro EB., 2007. Ciência e conservação na Serra dos Órgãos. Brasilia, DF: Instituto Chico Mendes de Conservação da Biodiversidade. 297p.

Del-Claro K., 2004. Comportamento Animal. Jundiaí, Editora e Livraria Conceito. 132p.

Emmons LH, Feer F., 1997. Neotropical Rainforest Mammals: a Field Guide. 2 ed. The University of Chicago Press. 396p. 
Ferreira GA, Nakano-Oliveira E, Genaro G, LacerdaChaves AK. Diet of the coati Nasua nasua (Carnivora: Procyonidae) in an area of woodland inserted in an urban environment in Brazil. Revista Chilena de História Natural, v. 86, p. 95-102, 2013.

Fortin JK et al. Impacts of human recreation on brown bears (Ursus arctos): A review and new management tool. PLoS One 11, 1-26, 2016.

Geffroy B, Samia DSMM, Bessa E, Blumstein DT. How Nature-Based Tourism Might Increase Prey Vulnerability to Predators. Trends Ecol. Evol. 30, 755-765, 2015.

Goldenberg SZ, Douglas-Hamilton I, Daballen D, Wittemyer G. Challenges of using behavior to monitor anthropogenic impacts on wildlife: a case study on illegal killing of African elephants. Anim. Conserv. 20, 215-224, 2017.

Guebert FM., 2008. Ecologia alimentar e consumo de material inorgânico por tartarugas verdes, Chelonia mydas, no litoral do estado do Paraná. Dissertação (Mestrado em Ciênciass Biológicas). Universidade Federal do Paraná. 76p.

Hirsch BT, Malpass E, Di Blanco YE. Interindividual spacing affects the finder share in ring-tailed coatis (Nasua nasua) Behavioral Ecology (2019), XX(XX), 1-7, 2019.

ICMBio, 2020. Painel dinâmico de informações. http:// qv.icmbio.gov.br/. Acesso em 23/11/2020.

Ipiranga ASR. A imagem fotográfica como uma questão de método. In: Congresso Brasileiro De Estudos Organizacionais, 4., Porto Alegre, out., 2016. p. 1-17. 2016.

Leung Yu-Fai, Spenceley Anna, Hvenegaard Glen, Buckley Ralf (eds.)., 2019. Turismo e gestão da visitação em áreas protegidas. Diretrizes para sustentabilidade. Série Diretrizes para melhores Práticas para Áreas Protegidas No. 27, Gland, Suiça: UICN. xii + 120 pp.

Moraes MFD, da Silva MX, Tebaldi JH, Lux Hoppe, EG. Parasitological assessment of wild ring-tailed coatis (Nasua nasua) from the Brazilian Atlantic rainforest. IJP: Parasites and Wildlife, 9, 154-158, 2019.

Mossaz A, Buckley RC, Castley JG. Ecotourism contributions to conservation of African big cats. J. Nat. Conserv. 28, 112-118, 2015.

Mostafavi E, Eftekhari Z, Jabbari N, Gheibi P. Transmission of COVID-19 between Animals and Humans: a Challenge for the Scientists. J Med Microbiol Infect Dis. 9 (1): 1-4, 2021.

Müllner A, Eduard Linsenmair K, Wikelski M. Exposure to ecotourism reduces survival and affects stress response in hoatzin chicks (Opisthocomus hoazin). Biol. Conserv. 118, 549-558, 2004.
Orams, MB. Feeding wildlife as a tourism attraction: a review of issues and impacts. Tourism Management, 23(3), 281-293, 2002.

Pickering CM, Norman P. Comparing impacts between formal and informal recreational trails. J. Environ. Manage. 193, 270-279, 2017.

Redford KH, Stearman AML. Notas sobre la biologia de tres procionidos simpatricos bolivianos (Mammalia, Procyonidae). Ecología en Bolivia, 21: 35- 44, 1993.

Riekehr Júnior LE et al. Parâmetros comparativos de indicadores bioquímicos plasmáticos de duas populações de quatis (Nasua nasua - Linnaeus, 1766) com e sem ação antrópica. Arq. Bras. Med. Vet. Zootec., v.69, n.3, p.659-666, 2017.

Rizzini CT. 1997. Tratado de fitogeografia do Brasil. 2 ed. Âmbito Cultural, 747p.

Roe D, Leader Williams N, Dalai-Claiton B. 1997. Take only Photographys, leave only Photootprints: The environmental impacts of wildilife tourism. IIED widilife and development series $\mathrm{n}^{\circ} 10$.

Saj T, Sicotte P, Paterson JD. Influence of human food consumption on the time budget of vervets. International Journal of Primatology. v.20, p. 977- 994, 1999.

Senigaglia $\mathrm{V}$ et al. Meta-analyses 75 of whale-watching impact studies: Comparisons of cetacean responses to disturbance. Mar. Ecol. Prog. Ser. 542, 251-263, 2016.

SILVA T.M., 2003. A estruturação geomorfológica do Planalto Atlântico no Estado do Rio de Janeiro. In: Simpósio Brasileiro de Geografia Física Aplicada, 10., Rio de Janeiro. Anais do X SBGFA, Rio de Janeiro: UERJ.

Souza TVS, Thapa B, Rodrigues CGO, Imorid D. Economic impacts of tourism in protected areas of Brazil. Journal of Sustainable Tourism, 2017.

Spenceley A, Snyman S, Eagles PFJ (eds)., 2019. Diretrizes para parcerias e concessões para o turismo em áreas protegidas: Gerando receitas sustentáveis para a conservação e o desenvolvimento. Relatório para o Secretariado da Convenção sobre Diversidade Biológica e a UICN Janeiro de 2019. https://www.cbd. int/tourism/doc/tourism-partnerships-protected-areasportugues-web.pdf. Acesso em 27/11/2020.

Stein DS. 2015. Emissões vocais de quati Nasua nasua (Linnaeus, 1766) associadas a contextos comportamentais. Dissertação (Mestrado em Comportamento e Biologia Animal). Universidade Federal de Juiz de Fora, Juiz de Fora, MG. 91p.

Turton SM, Stork NE. Environmental impacts of tourism and recreation in the wet tropics. Living a Dyn. Trop. For. Landsc. 349-356, 2008. 
UNWTO e UNEP., 2005. Making Tourism More Sustainable: A Guide for Policy-Makers. Madrid and Paris: UNWTO and UNEP.

Wraith J, Pickering C. Tourism and recreation a global threat to orchids. Biodivers. Conserv. 26, 1-14, 2017.

\section{Material suplementar}

As figuras 1 a 5 mostram registros fotográficos de algumas categorias de comportamento observadas em grupos de quatis (Nasua nasua) na sede Teresópolis do Parque Nacional da Serra dos Órgãos, Rio de Janeiro, Brasil.

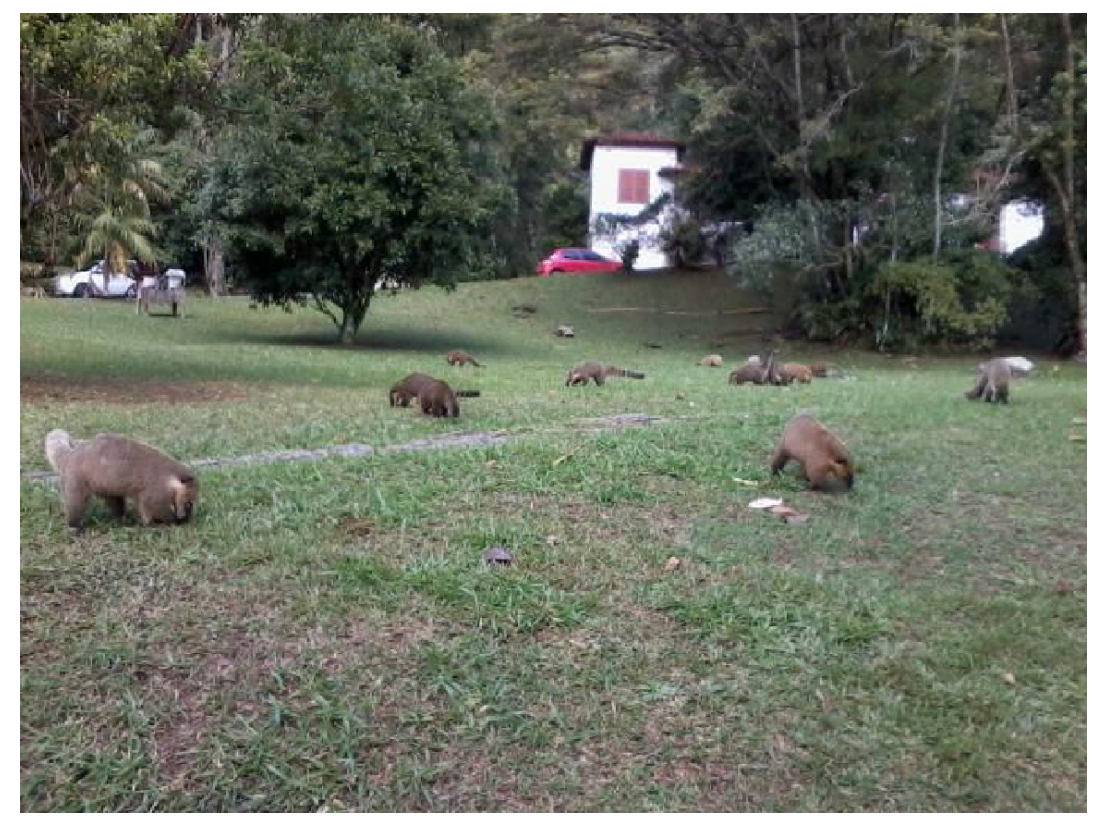

Figura 1 - Quatis forrageando no solo em local próximo à administração do Parque Nacional da Serra dos Órgãos, Teresópolis, Rio de Janeiro.

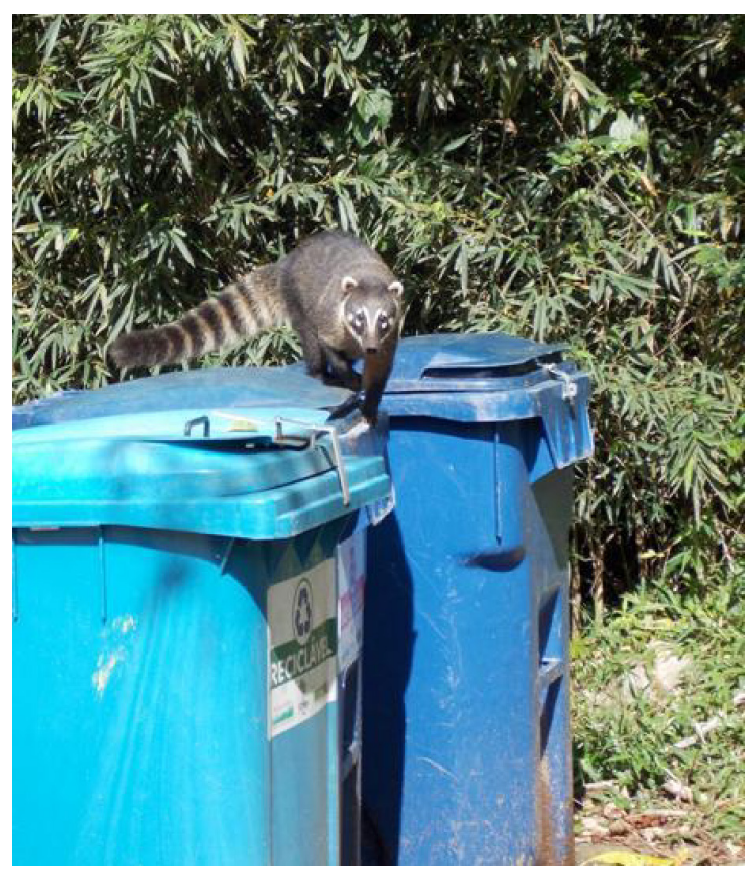

Figura 2 - Quati tentando abrir um latão com a trava "tijuca", durante o período do experimento de comparação entre os dois diferentes modelos de trava (de janeiro a julho de 2013 e julho de 2017 a março de 2018), no Parque Nacional da Serra dos Órgãos, Teresópolis, RJ. 


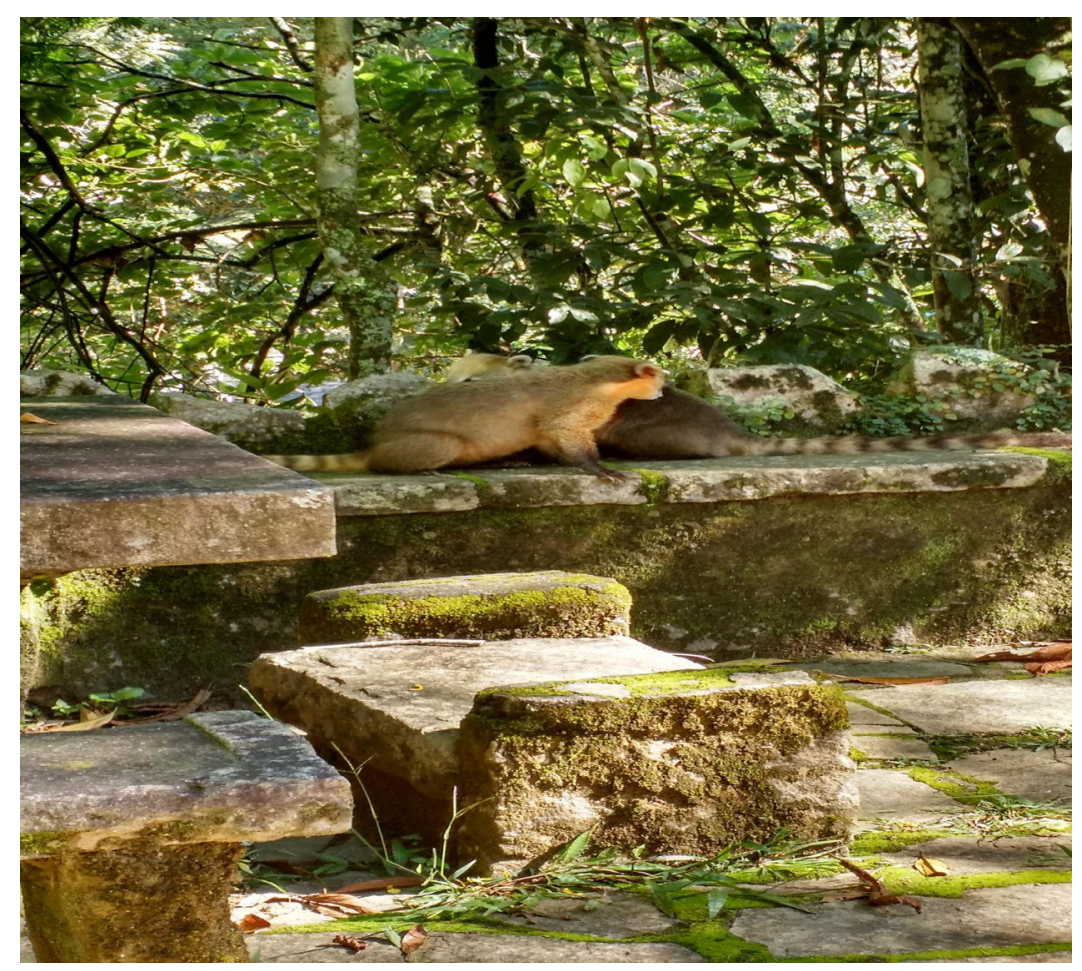

Figura 3 - Quatis praticando limpeza social, próximo ao alojamento do Parque Nacional da Serra dos Órgãos, Teresópolis, RJ.

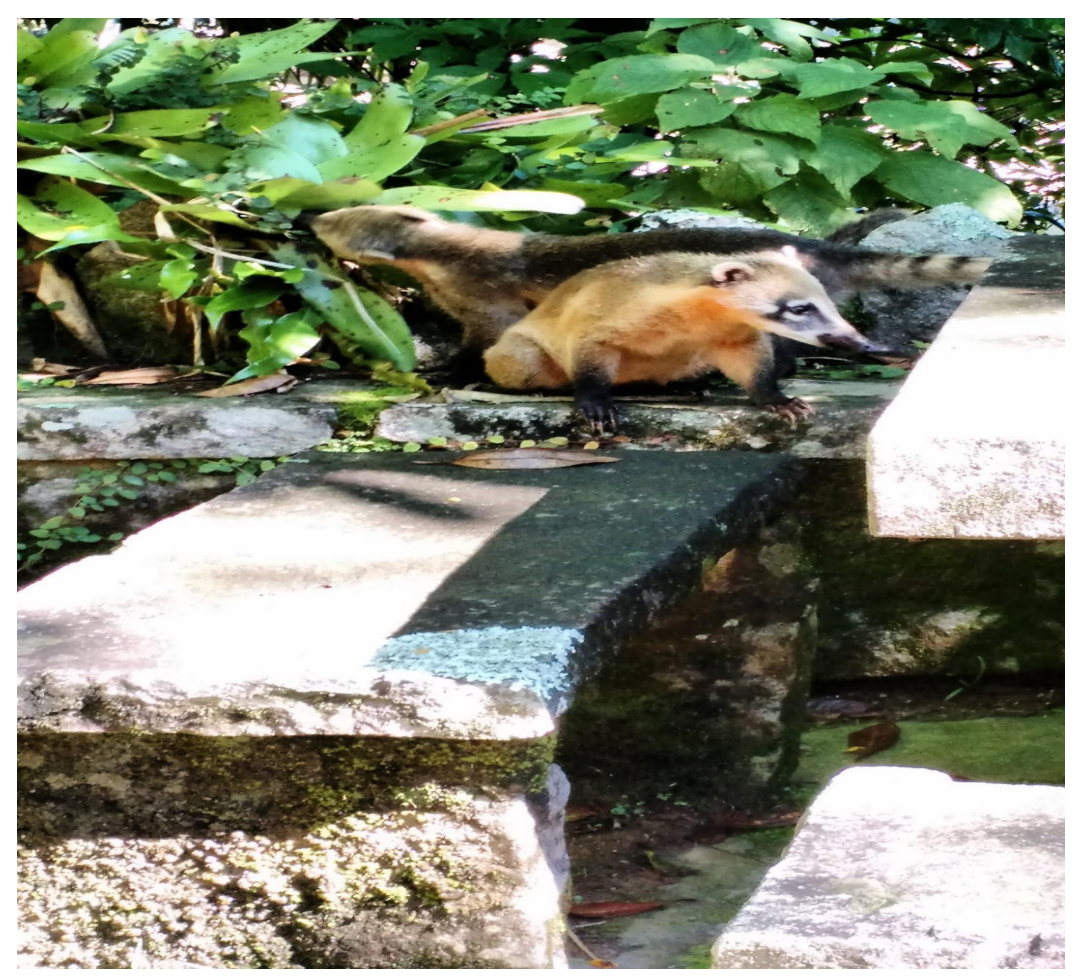

Figura 4 - Quati bebendo água de uma bromélia, próximo à administração do Parque Nacional da Serra dos Órgãos, Teresópolis, RJ. 


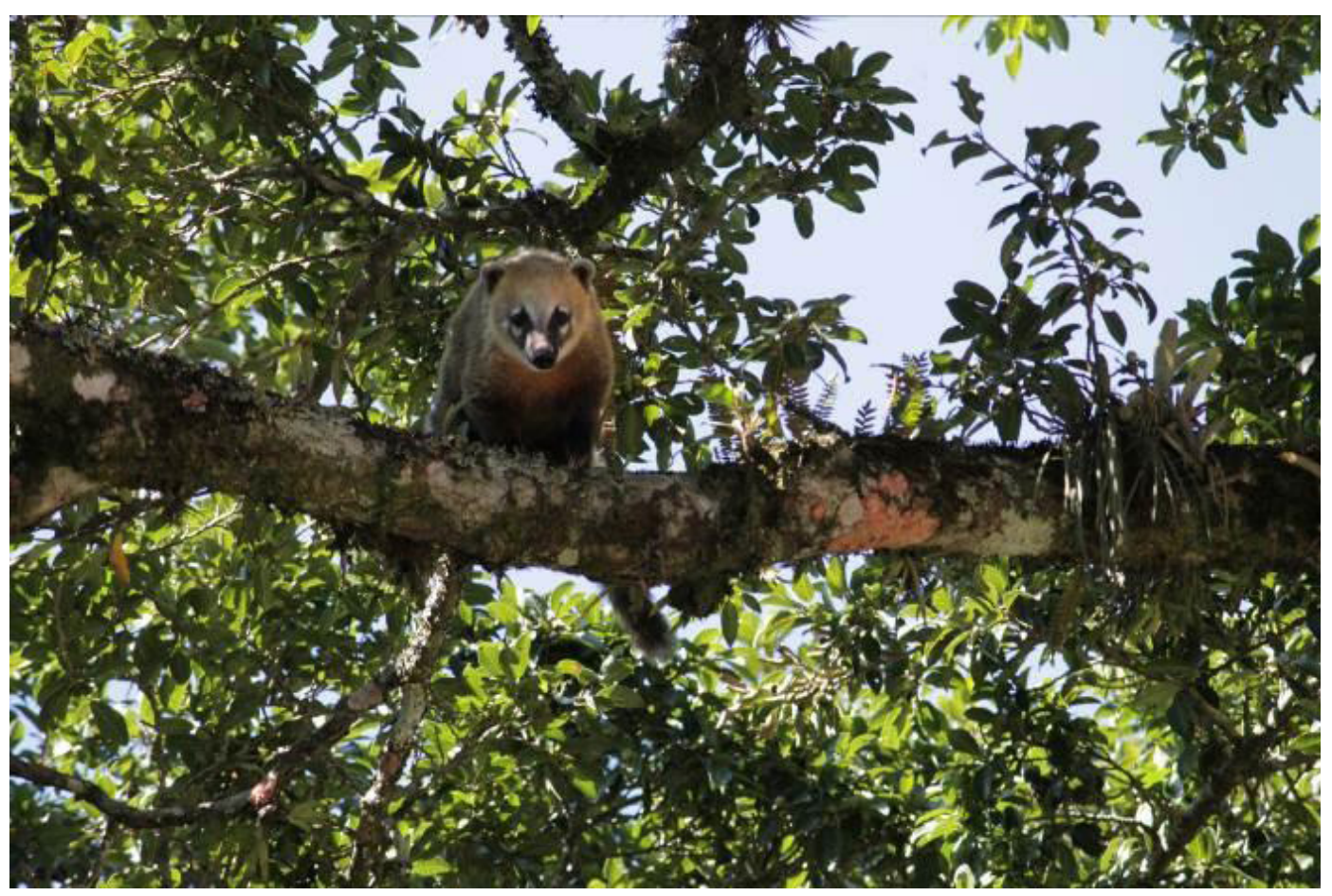

Figura 5 - Quati se deslocando sobre uma árvore da espécie Ficus insipida, próximo à administração do Parque Nacional da Serra dos Órgãos, Teresópolis, RJ

Biodiversidade Brasileira - BioBrasil.

Edição Temática: PIBIC

n. 1,2022

http://www.icmbio.gov.br/revistaeletronica/index.php/BioBR

Biodiversidade Brasileira é uma publicação eletrônica científica do Instituto Chico Mendes de

Conservação da Biodiversidade (ICMBio) que tem como objetivo fomentar a discussão e a disseminação de experiências em conservação e manejo, com foco em unidades de conservação $e$ espécies ameaçadas.

ISSN: 2236-2886 